\title{
Effect of Radiation on Physicochemical Properties of Peanuts
}

\author{
S. BALAKUMAR ${ }^{1 *}$, R.SANKARESWARI ${ }^{2}$ and A. ANIS MARY SARANYA ${ }^{1}$
}

${ }^{1}$ Centre for Scientific and Applied Research, PSN College of Engineering and Technology, Tirunelveli-627 152, Tamilnadu, India

${ }^{2}$ Pope's College, Sawyerpuram- 628251, Tiruchendure, Taminadu, India

Tirunelveli-627152, Tamilnadu, India

profbalakumar1951@gmail.com

Received 16 February 2016 / Accepted 26 February 2016

\begin{abstract}
Peanut (Arachis hypogaea) belongs to legume family. Its oil prevents heart disease and lowers cholesterol. The peanut kernels are infected by the fungus Aspergillus due to poor storage conditions. So the groundnut oil extracted shows undesirable properties. The fungal growth is prevented by electron beam irradiation. A study of the physicochemical properties like acid value, peroxide value, iodine value and moisture content before and after irradiation establishes the effectiveness of electron beam irradiation in the annihilation of fungal growth in kernels. The investigation confirms that electron beam irradiation helps to maintain the quality of oil.
\end{abstract}

Keywords: Peanut kernels, Physicochemical properties, Electron beam irradiation

\section{Introduction}

Peanuts are one of the most important oil crops in the world. They are the most nutrient dense nuts containing vitamin E, niacin, protein, magnesium, copper and phosphorous all of which may benefit health and help prevent chronic disease, including heart disease, diabetes and cancer ${ }^{1}$. Peanut oil is high in mono saturated "good" fat which help to lower cholesterol and decrease appetite as an aid to weight loss ${ }^{2,3}$. High antioxidant contents of peanuts lead to their cardio-protective benefits. Aspergillusflavus and Aspergillusniger species cause decay of peanut kernels. The fungus aspergillus appears in the form of greenish, smoky patches on peanut. This mostly happened due to poor storage conditions which allow pods or kernels to become damaged and contaminated ${ }^{4}$. The extent of contamination will vary with geographic location, agricultural and agronomic practices and the susceptibility of commodities to fungal invasion during pre-harvest, storage and processing periods.

Irradiation kills bacteria and other pathogens, its higher energy breaks chemical bonds in molecules that are vital for cell growth and integrity. Electron beam irradiation is a commercially successful technology for irradiating food products. The superfast process 
allows dose validation to be completed in a short time. This technology does not leave chemical residues in the products being irradiated which are totally environment friendly. The groundnut oil was analyzed for physicochemical properties such as iodine value, peroxide value, acid value and moisture content before and after irradiation. The aim of the study was to reduce fungal growth on peanut kernel using electron beam irradiation without changing quality of the groundnut oil.

\section{Experimental}

Five samples of shelled groundnut were collected from groundnut harvesting area (Figure 1), transported in polythene bags to the laboratory. The seeds were pealed by hand and all kernels were stored at four different temperatures of $30^{\circ}, 35^{\circ}, 40^{\circ}$ and $45^{\circ} \mathrm{C}$ in an incubator.

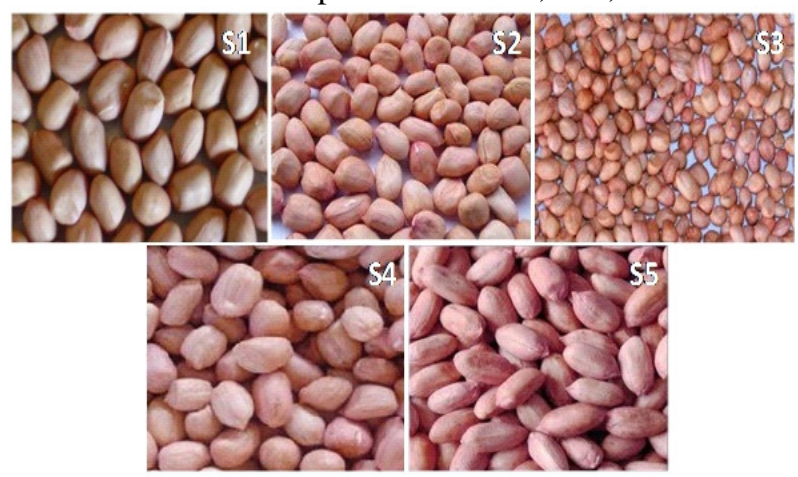

Figure 1. Selected groundnut samples

(S1-TMV7. S2-TMV13, S3-JL24, S4-VRI2, S5-VRIgn5)

\section{Extraction of oil for analysis}

The seeds were stored under dry condition prior to analysis. Extraction was carried out using soxhlet apparatus using $n$-hexane as solvent. The peanuts were dried at room temperature, peeled and crushed using mortar and pestle. $30 \mathrm{~g}$ of Peanut kernels were crushed well and poured into an iodine flask. $80 \mathrm{~mL}$ of $n$-hexane were added to the sample and was inserted in the centre of the magnetic stirrer. The apparatus was heated at $40-60{ }^{\circ} \mathrm{C}$. When the solvent was boiling the vapours run through the top of the lid. The liquid condensate dripped into the filter paper in the centre which contained the solid sample to be extracted. The extract passes through the pores of the filter paper. The apparatus was left to run for $2 \mathrm{~h}$. It was then removed from magnetic stirrer. It was dried and weighed again to determine the amount of oil extracted.

\section{Determination of physicochemical properties}

\section{Acid value}

Acid value is defined as the number of milligrams of sodium hydroxide required to neutralize the free fatty acids present in one gram of fat. Acid value was determined by titrimetric method of Pearson ${ }^{5} .5 \mathrm{~g}$ of the oil was weighed and $75 \mathrm{~mL}$ of hot neutral alcohol was added with a few drops of phenolphthalein. The mixture was shaken vigorously and titrated with $0.1 \mathrm{M} \mathrm{NaOH}$ solution with constant stirring until the pink color remains permanent. 


\section{Iodine value}

Iodine value of an oil is the number of grams of iodine absorbed by $100 \mathrm{~g}$ of the oil, when determined by using Wij's solution. $0.3 \mathrm{~g}$ of oil was weighed accurately in iodine flask and $20 \mathrm{~mL}$ chloroform and $20 \mathrm{~mL}$ of Wij's solution were added and stored in dark place for $45 \mathrm{~min}$. After removal from dark place, $15 \mathrm{~mL}$ of $10 \% \mathrm{KI}$ solution was added followed by $1 \mathrm{~mL}$ starch solution. Now it was titrated against $0.1 \mathrm{~N}$ sodium thiosulphate solution until the blue color disappeared indicating the end point. Blank solution was titrated without the oil sample.

Iodine value $=\left(v_{1}-v_{2}\right) \times$ Normality of thio $\times 126.7 \times 100 /$ Weight of oil $\times 1000$ where $\mathrm{v}_{1}$ - Blank titre value; $\mathrm{v}_{2}-$ sample titre value

\section{Peroxide value}

$5 \mathrm{~g}$ of oil was taken in $250 \mathrm{~mL}$ iodine flask and $30 \mathrm{~mL}$ of hydrogen peroxide solution and 1 $\mathrm{mL}$ of fresh KI solution were added. Color changed to light yellow and kept in dark place for exactly one minute. Then $30 \mathrm{~mL}$ of water and one or two $\mathrm{mL}$ of starch indicator were added. This was titrated against $0.01 \mathrm{~N}$ thio solution, disappearance of yellow color was the end point.

\section{Peroxide value $=$ Volume of thio $\times$ Normality of thio $\times 1000 /$ weight of sample}

\section{Determination of moisture content}

Moisture content of oils and fats is the loss in mass of the sample on heating at $105{ }^{\circ} \mathrm{C}$ under operating conditions specified. To a previously dried and tarred dish, about 5-10 g of oil weighed accurately was taken. Loosen the lid of the dish and heated, in an oven at $105^{\circ} \mathrm{C}$ for $1 \mathrm{~h}$. The dish was removed from oven, cooled in the esiccators and weighed. This process was repeated until change in weight between two successive observations does not exceed $1 \mathrm{mg}$.

Moisture and volatile matter $=W_{l} \times 100 / W$, Percent by weight, where, $\mathrm{W}_{1}=$ Loss in $\mathrm{g}$ of the material on drying, $\mathrm{W}=$ Weight in $\mathrm{g}$ of the material taken for test.

\section{Results and Discussion}

The study was carried out on five different samples viz., TMV7, TMV13, JL24, VRI2, VRIgn4. All the five samples were mixed with infected seeds to give different composition i.e., 6, 10, 16, 20\% of infection. The infected samples along with the control with no infection are kept in an incubator at four different temperatures $30,35,40$ and $45{ }^{\circ} \mathrm{C}$. These temperatures are considered because in ground oil industry the storage temperatures of groundnut vary from 30 to $45{ }^{\circ} \mathrm{C}$. The samples were kept in the incubator for a period of six months which is the normal period of storage in oil industry. The physicochemical properties of the four different infected samples were determined at regular intervals of thirty days for each temperature. In this paper the author is presenting the results of the study on one variety of groundnut viz., (TMV7) at a temperature of $30{ }^{\circ} \mathrm{C}$ for a period of 1 and 3 months in Table 1.

As the percentage of infection increases from 6 to 20, the oil content decreases progressively. This is an expected result of infection. The density of oil extracted remains almost constant indicating that there is no rancidity over six months at $30{ }^{\circ} \mathrm{C}$. The moisture content also does not show significant changes on infection and also with increasing storage time. According to Demian ${ }^{6}$, the acid value is used to measure the extent to which glyceride in oil has been decomposed by lipase and other actions such as light and heat and that its determination is often used as general indication of the condition and edibility of oils ${ }^{6}$. 
Table 1. Physicochemical properties of infected samples in $1^{\text {st }}$ and $3^{\text {rd }}$ months at $30{ }^{\circ} \mathrm{C}$

\begin{tabular}{|c|c|c|c|c|c|c|c|c|c|c|c|c|c|}
\hline \multirow[b]{2}{*}{$\begin{array}{l}\dot{0} \\
\dot{z} \\
\dot{n}\end{array}$} & & \multicolumn{6}{|c|}{$1^{\text {st }}$ month } & \multicolumn{6}{|c|}{$3^{\text {rd }}$ month } \\
\hline & 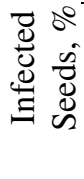 & $\begin{array}{l}\overrightarrow{0} \\
\stackrel{0}{0} \\
000 \\
\frac{0}{0}\end{array}$ & 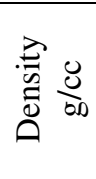 & 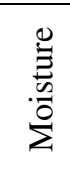 & 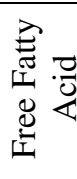 & 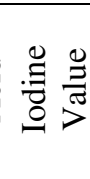 & 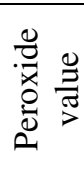 & $\begin{array}{l}\overrightarrow{\tilde{0}} \\
\stackrel{0}{0} \\
0 \\
\overline{0}\end{array}$ & $\begin{array}{l}\stackrel{\overrightarrow{0}}{0} \\
\frac{0}{0} \\
00\end{array}$ & 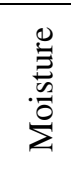 & 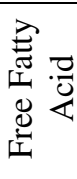 & 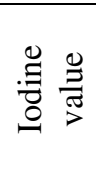 & 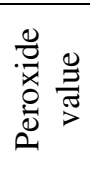 \\
\hline 1 & 0 & 42.1 & & & 0.3 & 9 & & .11 & & & 1. & & \\
\hline 2 & 10 & 5.38 & 0.808 & .15 & 2.2 & 95 & & 44.21 & 0.808 & 5.14 & 2.8 & & 0.11 \\
\hline J & 16 & 43.28 & 0.910 & 5.08 & 2.3 & 95.85 & 0 . & 43.18 & 0.873 & 5.38 & 3.2 & 95.55 & 0.12 \\
\hline 4 & 20 & 41.13 & 0.857 & 5.11 & 2.6 & 96.72 & 0.15 & 45.10 & 0.896 & 5.77 & 4.9 & 94.05 & 0.16 \\
\hline
\end{tabular}

Higher fatty acid value is an indication of lower quality. However the value is below $5 \%$ which indicate that the oil is suitable for edible purposes ${ }^{7}$. There is not much change in free fatty acid content on storage for six months. But with increase in the percentage of infection, free fatty acid value also increases. Iodine value is a measure of the degree of unsaturation in oil and could be used to quantify the amount of double bonds present in the oil which reflects the susceptibility of oil to oxidation. The value is high and this reflected the presence of unsaturated fatty acids in the seed oil. Iodine value is in the range of 94-96. This value is comparable to the literature value of castor oils and olive oils, both of which are non-drying oils. Since the iodine value is less than 100 , it cannot be classified as semi drying oil. The iodine value also is in accordance with the standards prescribed by CODEX-STAN 210 [Codex Alimantarius standard for named vegetable oils which is between 86-107] ${ }^{8}$.

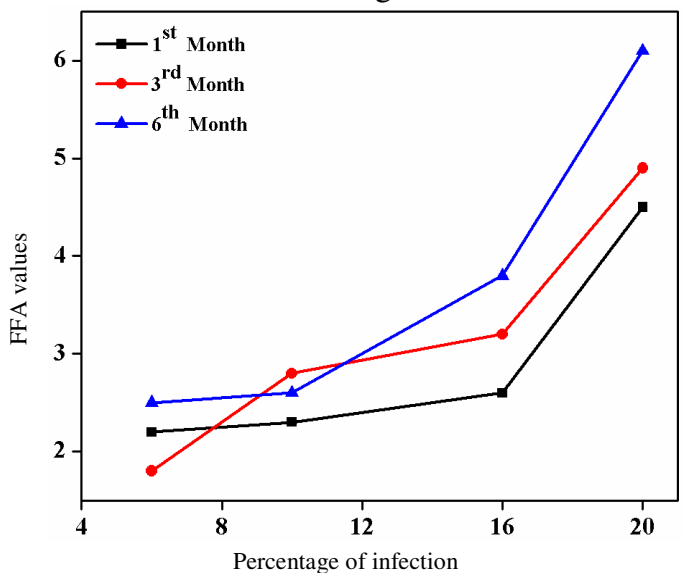

Figure 2. Free fatty acid values (FFA) against percentage of infection at different months

Peroxide value indicates the degree of rancidity and provides a measure of the prospective life of the oil. It shows the influence of air, light and time on the oil and measures the amount of oxidation due to these factors at any specific time. It is generally thought that peroxides arises in vegetable oils from the attack by oxygen on the $-\mathrm{CH}_{2}$ group between carbon double bonds. These hydrogen atoms are reactive and peroxides are formed. The breakdown of peroxides can be catalyzed by acids or heat and yields a number of other breakdown products, which contribute to the flavor, pleasant or otherwise of oxidized oils. The peroxide value shows a gradual increase from 0.1 to 0.18 with increase of infection from 6 to $20 \%$ in all the months at $30{ }^{\circ} \mathrm{C}$. This shows that as the percentage of infection increases the oil becomes susceptible for oxidation. Therefore the quality of the oil decreases. 
The physicochemical properties except peroxide value and free fatty acid value remains almost constant. As the time of storage increases from one to six month, the peroxide value shows progressive increase and the free fatty acid also shows similar trend. This indicates the onset of decay process with time $e^{9,10}$. The two values put together constitute rancidity setting which is an inhibitive factor in the quality of oil. The same trend is observed for other temperatures $35,40,45^{\circ} \mathrm{C}$ also.

\section{Electron beam irradiation of groundnut kernel}

E-beam irradiation is a fairly new technology, joining x-rays and gamma radiation. E-beam irradiation is cheaper to use because the facilties do not require thick walls, containment pools or disposal of radioactive materials. Also, the food can travel through the irradiation facility much more quickly because e-beams have higher energy and penetrate more quickly than gamma rays.

The samples were exposed to Electron Beam Irradiation (EBI) at Microtron center, Mangalore University, Karnataka. Five samples of Aspergillus infected groundnut seed samples similarly packed without exposure to irradiation were used as control. The sample mixed with different percentages of infected seeds were also subjected to same type of irradiation. In a separate study on electron beam irradiation on aspergillus infected groundnut kernel it has been found that the optimum dosage for reducing the infection is $800 \mathrm{~Gy}$. Therefore in this study the groundnut samples are subjected to electron beam irradiation of $800 \mathrm{~Gy}$ only.

\section{Study of physicochemical properties after irradiation}

Electron beam irradiation has an impact on the physicochemical properties of oil and the results for groundnut sample of TMV7 are presented here in Tables 2 and 3.

Table 2. Study of physicochemical properties of infected samples in $1^{\text {st }}$ and $3^{\text {rd }}$ months at $30^{\circ} \mathrm{C}$ (after irradiation for TMV7)

\begin{tabular}{|c|c|c|c|c|c|c|c|c|c|c|c|c|c|}
\hline \multirow[b]{2}{*}{$\begin{array}{l}\not \\
\dot{z} \\
\text {. }\end{array}$} & \multirow[b]{2}{*}{ 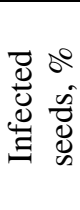 } & \multicolumn{6}{|c|}{$1^{\text {st }}$ month } & \multicolumn{6}{|c|}{$3^{\text {rd }}$ month } \\
\hline & & 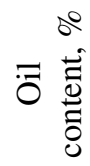 & 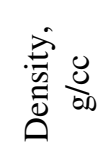 & 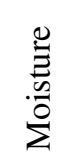 & 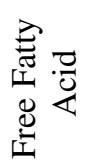 & 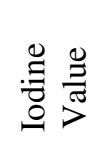 & 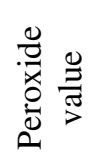 & 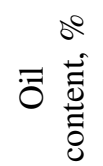 & 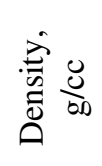 & $\begin{array}{l}\stackrel{0}{\Xi} \\
\frac{\mathscr{D}}{0} \\
\sum\end{array}$ & 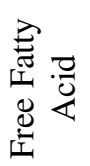 & 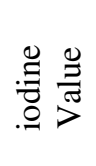 & 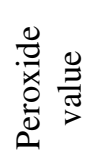 \\
\hline 1 & 6 & 14.41 & & & 0 . & & & 106 & & 5.01 & 1 . & & \\
\hline 2 & 10 & & & & 1. & & & & & 5.09 & 1. & & \\
\hline 3 & 16 & 45.35 & 0.83 & 5.11 & 1.5 & 95.07 & 0 & 40.23 & 0.8 & 5.91 & 1.7 & 96.22 & 0.11 \\
\hline 4 & 20 & 45.45 & 0.890 & 5.01 & 2.1 & 95.15 & 0.11 & 40.58 & 0.817 & 5.19 & 2.1 & 94.11 & 0.12 \\
\hline
\end{tabular}

Irradiation reduces the free fatty acid and peroxide value content. Iodine value remains almost constant. Further the moisture content of the sample also decreases. Also the FFA and peroxide values are decreased after irradiation as shown in Tables 3.

Table 3. Comparison of free fatty acid and peroxide values of infected samples in $1^{\text {st }}$ month at $30^{\circ} \mathrm{C}$ (TMV7)

\begin{tabular}{cccccc}
\hline \multirow{2}{*}{$\begin{array}{c}\text { S. } \\
\text { No. }\end{array}$} & \% of & \multicolumn{2}{c}{ Free fatty acid values } & \multicolumn{2}{c}{ Peroxide values } \\
\cline { 3 - 6 } & & $\begin{array}{c}\text { Before } \\
\text { irradiation }\end{array}$ & $\begin{array}{c}\text { After } \\
\text { irradiation }\end{array}$ & $\begin{array}{c}\text { Before } \\
\text { irradiation }\end{array}$ & $\begin{array}{c}\text { After } \\
\text { irradiation }\end{array}$ \\
\hline 1. & 6 & 2.2 & 0.9 & 0.10 & 0.1 \\
2. & 10 & 2.3 & 1.1 & 0.11 & 0.1 \\
3. & 16 & 2.6 & 1.5 & 0.15 & 0.1 \\
4. & 20 & 4.5 & 2.1 & 0.18 & 0.11 \\
\hline
\end{tabular}




\section{Conclusion}

The results of the studies on the physicochemical properties of the oil extracted from groundnut TMV7 is before and after irradiation for a period of six months indicate that the quality of the oil decreases with increase of infection and time of storage of the groundnut kernel. However electron beam irradiation is successful in maintaining the quality of the oil for about six months, even for groundnut samples contaminated with infection seed. Thus electron beam irradiation can be a successful tool for maintaining the quality of the oil in groundnut kernels.

\section{Acknowledgement}

One of the authors Dr. S. Balakumar gratefully acknowledge the financial support received from the Board of Research in Nuclear Science Department of Atomic Energy (BRNS-DAE), Mumbai, India with File No.2010/34/21/BRNS/No.0087 to carry out this research work.

\section{References}

1. Swati Mandloi, Radadia B B, Manish Visavadia and Ashokkumar Vaghela, Weekly Sci Res J., 2014, 1(30), 2321-7871; DOI:10.9780/ 2321-7871/1202013/53

2. $\quad$ Kris-Etherton P M, Pearson T A and Wan Y, Am J Clin Nutri., 1999, 70(6), 1009-1015.

3. Lokko P, Lartey A, Armar-Klemesu M and Mattes R D, Int J Food Sci Nutri., 2007, 58(3), 190-200.

4. Kabagambo E K, Baylin A and Ascherin A and Compos H, Rica J Nutr., 2005, 135(11), 2674-2679.

5. Pearson D, The Chemical Analysis of Food (6 ${ }^{\text {th }}$ Ed, ), Churchill J A, London. 1970, 510-515.

6. Demian M J, Principles of food chemistry, $2^{\text {nd }}$ Ed., Van Nostrond Reinhold International Company Ltd, London, England. 1990, 37-38.

7. Esuono Ko and Odetokun S M, Rivista Italiana delle Sostanze Grasse, 1995, 72, 311-312.

8. http://www.fao.org/docrep/004/y2774e/y2774e04.htm

9. Kar A and Mital H C, Plant Food Human Nutri., 1999, 15, 13-67.

10. Ogbonnayachukwu and Yahayasadiq, J Food Technol., 2008, 6(5), 217-220. 